\title{
High literacy level, very low reading culture: an examination of the underlying causes of the Zimbabwean paradox
}

\author{
Godwin Makaudze \\ Great Zimbabwe University \\ Department of African Languages and Literature \\ Jairos Kangira \\ University of Namibia \\ Department of Language and literature Studies
}

\begin{abstract}
Zimbabwe currently boasts of one of the highest literacy levels in Africa. Paradoxically, such an encouraging state of affairs is not paralleled with a high reading culture. Instead, the high levels of literacy are undone by a very low reading culture. This paper is an exploration of the possible underlying causes of such a state of affairs as well as the possible intervention strategies. It used the qualitative paradigm, with interviews and semi-structured questionnaires being employed to extract information from selected teachers, learners, parents, readers, publishers and bookshop managers. For teachers, learners, readers and parents, random sampling was used whilst purposive sampling was used for publishers and bookshop managers. Data was discussed in accordance with the themes that emerged. The paper observed that the reasons of the paradox included: emphasis on passing the examination, high costs of living and of producing and accessing reading literature, paucity of serious works of art that illuminate life. Possible intervention strategies included: re-orienting the education system, partnerships meant to avail and subsidise accessibility of literature, re-orienting the Zimbabwean language policy and improving marketing strategies for literature.
\end{abstract}

\section{Keywords}

Literacy; reading culture; literature; Zimbabwe; paradox

\subsection{Introduction}

In Africa, Zimbabwe counts amongst the few nations with a very high literacy level. Statistics of literacy levels in Zimbabwe are placed at various percentages. The Zimbabwe Independent, of April 2014 puts it at 90\%, the United Nations Development Programme (UNDP) Digest of 2014 at 92\% (NewZimbabwe.com), and it is between $92-97 \%$ according to Munjanganja and Machawira (2014:8), while Zimbabwe National Statistical Agency (ZimStat) puts it at 97\% (Shoko 2014:5). The percentages vindicate very high levels of literacy. The majority of the population, both old and young, are able to read and write in English, Shona or Ndebele. One would expect such high levels of literacy to be ordinarily matched with an equally high reading culture. In other words, the higher the number of people who can read and write, the higher the desire for reading should be also. Existence of a reading culture would be vindicated by people motivated to buy and read books, magazines, newspapers or even subscribing to internet based sources of information, reading for leisure and for self-enlightenment. In other words, even without a pending examination, people with a reading culture should be seen enjoying reading various kinds of literature, just for the love of it.

With Zimbabwe, it sadly is not the case. Despite the unparalleled levels of competence in reading and writing, the citizens are amongst the least motivated readers. The Literature Festival of December 2014 held in Harare observed and lamented that, the dwindling reading culture is an issue which today's African writers and publishers are struggling to come to terms with (Tapureta 2014, p. 7). The statement 'to hide something from an African you must write it in a book' aptly applies to the Zimbabwean situation. Those at various levels of education, out of school or in various positions of employment exude very little motivation to read, except if they have a pending examination. Despite the existence of publishing houses and bookselling companies as well as the continued expansion of internet service providers, the zeal for reading is still painfully low. Then Longman's marketing manager summed it all:

One of the reasons for the few publications in the novels area is the realisation that Zimbabwe as a whole does not seem to read for leisure. Even supplementary books are meant for schools. Our market is inevitably the school. Some of the books are not good enough for the public, but the market is so small that we can't readily publish for it. Books are there but the market is not there. Unless we cultivate reading habits we will continue to rely on schools (Chiwome 2002:48).

Although the manager's complaint was directed towards few readers of the novel, it can be extended to include all forms of literature which includes newspapers, magazines and general books. His observation that they publish for the schools implicitly testifies that they have a forced readership in the form of school children. Again, whereas he felt the market was very small, a look at the Zimbabwean population which according to the census statistics of 2012 was around 13 million indicates that if the people had a reading culture, the market is good enough. Hence, it is clear that despite the fairly large population and high literacy, the people do not enjoy reading. This article thus sought to examine the underlying causes for the sorry state of affairs as well as ways of matching the literacy and reading culture levels.

\subsection{Underlying causes of the Zimbabwean paradox}




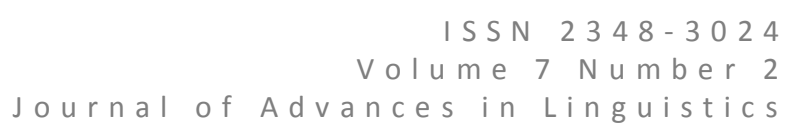

\subsection{Emphasis on passing the examination}

Teachers, headmasters, pupils and parents concurred that the education system in Zimbabwe is strongly inclined towards passing an examination. Five (5) Ordinary level passes constitute a pass, while at least two (2) Advanced level passes are good enough at that level. They stressed that those who pass have higher chances of progressing into higher levels of learning and boosting their chances of obtaining a professional qualification. Headmasters lamented that, the Ministry of Primary and Secondary Education descends heavily on schools whose overall pass rate is deemed unsatisfactory and that the same Ministry now ranks schools in order of their Ordinary and Advanced Level pass rates. Parents indicated that they took the ranking as an opportunity to see which schools were good enough for their children. As such, priority is now on passing the exam than one enjoying reading.

Headmasters and teachers testified that books that are phased out of the syllabus normally find their way into the storerooms and are replaced by those recommended for study. Teachers further stated that they encouraged their pupils to read books that were in the syllabus. Thus, to them, reading is limited to passing an examination. Learners interviewed also pointed out that they knew no other reading outside the prescribed texts in schools. It was gathered that, when a pupil held a book, the fundamental questions s/he asked himself was whether it was in the school syllabus. If not, then it was not worth spending time on. Thus, there seems to be no incentive in reading for leisure. Teachers argued that, owing to the low budget allocated for books, they normally ordered very few set-books for study at each level. In some cases, only one textbook could be bought, and meant for the teacher. Hence, learners depended on notes given by the teacher, who normally resorted to the drilling method, training learners to pass the exam. As such, learners pass without necessarily having read text books.

The researchers discovered that most schools developed their own teaching and learning policies in a bid to boost their learners' pass rates. Most school time tables did not have provisions for leisurely reading. The timetables ran from 6.45 in the morning to 3.30 in the afternoon. The timetables were so packed that the only available free times were break and lunch times. Sometimes only a single free period was available per day, which pupils normally used to finish off their written work. This left them with very little reading time. The packed timetables left the learners exhausted. Most learners indicated when schools closed they registered to do extra lessons. Most holiday lessons focused on past exams papers and how one could answer questions well. In University education, students lamented that the semesters are usually packed; with a student having to do an average of six (6) modules/courses per semester. Before the exam, a student is expected to have written and submitted at least a total of twelve (12) assignments. Hence, most of the reading done is meant to answer an assignment. This leaves the students with very little if any time for leisurely reading. Chiwome (1996:7) sums up the whole picture saying Zimbabwean education is so-certificate oriented that reading is rarely an end itself. Readers live and behave in accordance with the dictates of the education system. It was gathered that where newspapers are bought, especially in schools, they were linked to subjects like Economics and Management of Business. These included the Thursday Herald, Sunday Mail and the Financial Gazette. Thus, the buying and reading of newspapers at schools is again heavily linked to passing an examination. At all levels of learning, reading is considered a torture that one has to endure whilst in school and which one can escape from after completing.

\subsection{High costs of accessing reading literature}

Parents, school authorities and the general public indicated that the cost of buying books, magazines and daily newspapers or accessing them on internet was beyond the reach of many individuals, schools, institutions and other organisations in Zimbabwe. Publishing companies' managers stressed that they usually incur huge costs in the publishing process and in order to recoup their expenses, they peg prices of books highly. The researchers made a number of observations: prominent booksellers' (like Baroda Trading) imported books meant for schools and tertiary institutions. These were pegged at very high prices in a bid to recover the shipping costs. Thought-provoking works of art by writers from outside Zimbabwe, such as Chinua Achebe, Ngugi wa Thiongo, Okot p'Bitek if available, had prices higher than the majority of Zimbabwean readers could afford. Managers of booksellers in Masvingo and Gweru indicated that most people who came looking for certain titles were put off as soon as they were told the prices of the said titles, a testimony that the prices were higher than they would have anticipated.

Headmasters claimed that most schools realised little income in the form of fees. In the end, they allocated very little money towards the procurement of reading material. Stocking school libraries with newspapers and magazines was considered wasteful by guardians who paid fees for the children. As a result, schools prioritised and bought very few of those books recommended in the schools syllabus. In most schools, as many as up to ten (10) pupils shared a single text book, making access to it very difficult. Guardians complained that they were also asked to buy text books for their children because the schools could not afford them. The overburdened guardians usually failed to honour the request. Hence, the appetite for reading was neither sowed nor nurtured.

Tertiary students indicated that the government has since withdrawn the grants it used to give students, citing cash-flow challenges. These grants enabled students to buy books to read for academic and leisure purposes. It was not uncommon to have students who had personal libraries which had a variety of literature. With the scrapping off of the grants, students are now expected to pay for their accommodation, meals and transport; costs which are again passed on to the students' overburdened guardians. Institutions also no longer receive per capita grants they used to get from the government, hence, the libraries in most cases, have very old titles. Readers also indicated that although newspapers and other literature could now readily found on the internet, this facility was limited to those with an internet connection and it came with costs on the individual readers. Such operational costs were considered unsustainable, especially in an economically challenged environment such as obtains in Zimbabwe.

1199 | P a g e

october 2016

https://cirworld.com/ 


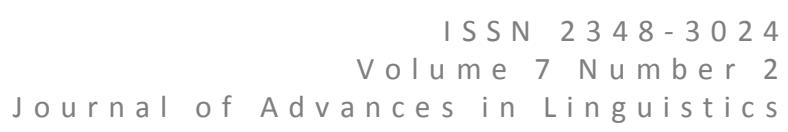

\subsection{High cost of living}

The cost of living in Zimbabwe is high, with the poverty datum line hovering around $\$ 511$ per household of six (ZimStat April 2013:38), an amount hardly earned by the majority of the Zimbabwean population, most of whom are civil servants and the unemployed. According to information from the Ministry of Finance and Economic Development, as of January 2014 , a household of about six (6) needed close to $\$ 600.00$ to survive through a month. Unemployment rate in Zimbabwe stands at an estimated $90 \%$, meaning most of the people have no steady incomes with which to cater for the needs of their families. Thus, the majority of people struggle to make ends meet. Interviewees indicated that they struggle to meet daily needs of food, shelter and clothing. Some even take very long to pay fees for their children because they simply cannot afford. Some guardians disclosed that when they pay fees, they feel they have played their part in the education of their children. They believe the schools have to take over all the other costs. Yet, the schools also are caught up in the same wave of high cost of living. Boarding schools also spent a lot of money buying food necessities for pupils and end up allocating very little if any amount to the procurement of the adequate number of reading books for learners. Most day schools have cases of pupils who cannot pay the required fees for every term, making the running of schools, and the buying of reading texts a difficult endeavour. In the end, teachers are urged to be resourceful, to go out of their way and acquire information that they will teach their pupils.

Interviewees argued that they cannot afford to buy books, daily newspapers, or make daily subscriptions to access them or even buy magazines for leisurely reading. Reading of newspapers daily, and sometimes magazines, is something limited to very few well-thriving companies and institutions. Even so, in these companies and institutions, the newspapers are bought for the top employees; making them inaccessible to the majority at lower levels. It was noted that the top employees only have access to newspapers not because they buy them themselves, but because the company buys for them. Otherwise if they had to dig into their pockets no one would afford. Workers indicated they have access to the newspapers many days after the top employees have finished reading them and when some of the pages could be torn or missing. They stressed that the junior employees were not expected to be seen reading newspapers as this was considered insubordination. Doing so was considered jeopardising production. In most cases, when junior employees read newspapers, their intention was to check on job advertisements. Thus, theirs was not really a reading culture, but keenness to find better working places.

\subsection{High costs of publishing and/or re-printing books}

According Chiwome (1996:7), the publisher is in the business of selling words. Seddon (1966:91) adds that "the only question a publisher asks him/herself when he holds a manuscript is 'Does it sell?" If it sells, then it is worth publishing since it guarantees the publisher of returns and a profit. If it does not sell, then it is not worth publishing. Publishers lamented that the costs of publishing are so huge that if one does not consider its economic value it can negatively affect the financial standing of a company. They singled out the machinery used in publishing as very expensive to import, so are expenses related to editing, typesetting and printing. They indicated that they now ask the authors to pay for the initial costs incurred in the publishing of their books (Uzochukwu 2005:31) so that when the book flops on the market publishers do not incur huge losses. In most cases, the authors are the same citizens who are struggling to make ends meet in a trying economy.

Publishers indicated that their focus is on a huge market, which happens to be the school. A prescribed book sells more than an unprescribed one (Chiwome 1996:8). Once a book has been recommended as a text or a set-book for study in schools then it will surely sell and fetch some profit. Hence, books can only be published or re-printed if they are recommended as set texts. Thus, in Zimbabwe, publishing means publishing for the schools hence, writing also implicitly means writing for the schools. Researchers noted that most bookselling shops in Masvingo, such as Kingstons, Mambo Bookshop (Roman Catholic), Mabhuku Bookshop (Reformed Church in Zimbabwe) only have books that were and are set-books in schools. This could be the case across Zimbabwe. Asked why they had lots of stationary and a few old titles of books, the branch manager of Kingstons Booksellers in Masvingo disclosed that they only order titles that are set-books in schools. To this effect, they work hand-in-glove with the Ministry of Primary and Secondary Education and the publishing companies. This leaves the majority of elders with little if any literature to enjoy reading. In the end, elders only have newspapers as reading literature, which again have been seen to be inaccessible to the majority.

\subsection{English-Indigenous language ambivalence}

Colonialism upheld English as the official language while Shona and Ndebele were vernacularised. The mother tongues were to be used in lower primary school, that is, in basic education (Campbell and Gwete 1998:208). Those few Africans who proceeded beyond basic education stage subsequently switched to English as a medium of instruction and communication (Gudhlanga and Makaudze 2007:4). Initially, indigenous languages were not taught in schools and universities. No serious learning was ever considered possible in the indigenous languages (Gudhlanga and Makaudze 2007:5). Indigenous languages like Shona and Ndebele were associated with rural poverty from which they people strove to escape. Candidates strove towards passing English, the language without which the Cambridge School Certificate would not be valid (Chiwome 1996:7).

The situation has not significantly changed. As a result of the historical binary of English and indigenous languages, today, English is still considered a prerequisite for obtaining a job and acceptance into colleges and universities. Indigenous languages are still shunned. Teachers of indigenous languages are looked down upon. Zimbabwean students drop an indigenous language as a subject even when they have been in excelling in it and even refuse to enrol at college or university to study them. At Great Zimbabwe University where the indigenous languages are taught in their exclusive mediums, the researchers noted students do everything possible to be allowed to change to other programmes. Ironically,

$1200 \mid P$ a g e

October 2016

https://cirworld.com/ 


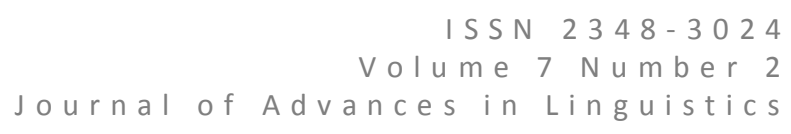

most of those who have studied other programmes use their indigenous languages in the greater part of their life; at workplaces and in communicating and even in explaining difficult phenomena in their 'prestigious' disciplines. Thus although they love English, the platforms for its use remain official business, out of which they revert to their indigenous languages. The colonial situation regarding English language seems to have cascaded to contemporary Zimbabwe, "A little bit of English for everyone and a lot of English for a selected few" (Chiwome 2002:7). Zimbabweans interviewed testified that very few are comfortable in using English owing to its complexity as a foreign language. Very few are able to sustain a conversation in English. In the end, very few are comfortable in reading literature in the second and difficult English language. At the same time, they feel ashamed to be seen reading literature in indigenous languages, languages associated with rural poverty, lack of education and considered unimportant for a job or entry into a college. Teachers and learners testified that school libraries have more English than Shona literature, and despite that Shona books are relatively cheaper than books for other subjects, they are scarce in libraries. The paradox lies in that; whereas knowledge and skills are imparted exclusively in foreign languages, the daily tasks are performed mainly in indigenous languages. The apposition kills the passion for reading in either language.

\subsection{Early orthography and marginalisation of other languages}

When Doke (1932) came up with a unified orthography of Shona language, he also made recommendations that, only two indigenous languages be officially recognised in Zimbabwe, Shona and Ndebele. Speakers of Xichangana, Hwesa and Barwe, in the southern and north-eastern parts of Zimbabwe were made to sideline their languages and learn Shona as 'their' language. In Matebeleland, speakers of Venda, Kalanga, Nambya and Tonga were also made to learn Ndebele. Speakers of these languages testified that although they learnt and studied either Shona or Ndebele, they still spoke their mother tongue languages (which were not part of the school curriculum) away from the school. These studied other indigenous languages merely as a response to the dictates of the colonial system, but inwardly, they were bitter at being forced to abandon their mother tongues. So they just read literature in these other languages for the purposes of passing an examination and getting a job. Even today, much of the literature is still either in English, Shona or Ndebele; not in these minority languages. They declared that they cannot have the enthusiasm to read; whether in English, Shona or Ndebele because these were languages imposed on them. They do not identify with any of the official and national languages. They have no pride in them. Their distaste of the so-called official languages is bluntly by expressed by the then chairman of the Tonga Language Committee:

The issue of referring to Ndebele and Shona as main languages is like pointing a figure at oneself as being 'main'. Main to who? Every language is the main language to the speakers of that language. To say one's language is the 'main' is tantamount to saying somebody's child is the 'main' to me... (Mumpande 2006:14).

Hence, to them, reading literature in these imposed languages is the same as promoting the dearth of their own languages. Hence, they feel they are better off without reading.

\subsection{Paucity of serious works of work that illuminate life}

In Zimbabwe, there is paucity of literature that seriously illuminates life. Serious writing involves the exploration of issues to do with the people's basis of survival. In Zimbabwe, serious literature should expose, analyse and influence the political and economic being of the people. Many writers and publishers (italics, writer's own) complain that the Zimbabwean situation at the moment is such that they cannot tackle real and pertinent issues and treat them objectively (Gudhlanga and Makaudze 2007:10). The Zimbabwean situation has seen the emigration of many qualified personnel, the redistribution of land, the exploration of the vast mineral resource, the promulgation of many policies that have had a strong bearing on the people's lives. Sadly, such events have not given birth to serious and thought-provoking literature that is readily available in Zimbabwean bookshops country-wide. Though the situation has slightly changed with the emergence of such writers as Ignatius Mabasa and Chirikure Chirikure, Vitalis Nyawaranda's complaint is still largely vindicated, "I did Shona at the University. In our literature works, we used to argue about the quality of novels we were reading at university level" (Chiwome 2002).

Even today, there is very little literature to challenge readers at all levels. Staunton observes that school children need high quality books not the second best that government recommends to them; if they read good books when they are young, they would continue to read for the rest of their lives (Chiwome 2002). Teachers and readers interviewed lamented that most book shelves in Zimbabwe are inundated with literature that does little to raise the people's awareness of their condition and how it can be ameliorated. In fact, they are filled with literature for use in schools. Much of such literature is often a flight from reality; diverting readers' minds solely towards romantic trivialities. Some of the issues presented by life are perceived to be so sensitive as to impose self-censorship on writers and even publishers. With such a dearth in literature of engagement, readers feel undone by both writers and publishers and so shun reading the available literature which does not meet their expectations.

\subsection{Towards a reading culture}

Despite the pathetic state of affairs explained, interviewees concurred that; the situation can still be improved. A number of ways were suggested, among them: reorienting the schools system, subsidising the costs of publishing and/or printing books, partnerships meant to subsidise accessibility of literature, introducing community and more school libraries, and improving marketing strategies for books.

\subsection{Reorienting the school system}




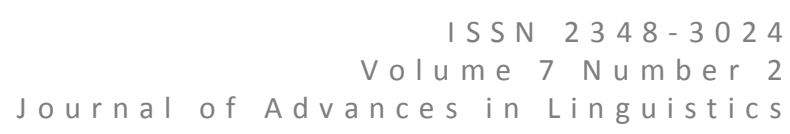

The general public urged that the Zimbabwean school system be reoriented so that focus and emphasis are not placed on passing examinations, but on striking a balance between high literacy and the reading culture. Since people are more worried with passing an exam, there may be need for a general examination at the various levels so that pupils' general reading is cultivated and nurtured. Or, books meant for the school syllabus can be examined together with other aspects found in one's general reading. Such an approach would have a bearing on the structure of the school timetables which then will be adjusted to give pupils amble time to enjoy reading widely.

\subsection{Partnerships}

Publishers wished for ways of subsidising the costs of publishing books and newspapers and availing them to readers in all corners of the country; together with modern facilities of accessing information such as the internet. Already, there are initiatives in that regard. An encouraging development that took place during the era of the Government of National Unity (GNU) was the partnership between government and organisations as United Nations Children's Education Fund (UNICEF). The partnership saw the donation of reading materials to schools in many provinces of the country. Headmasters and teachers testified that pupil-book ratio was improved from an estimated one book to thirty pupils to almost one as to one. This opened avenues for pupils to have a feel, and enjoy the privilege of reading books as much as they wanted. Thus provision of reading literature is an important step in cultivating a reading culture. Practitioners urged that a similar gesture be extended to include provision of internet services and other varieties of literature that appeal to various tastes of the readers at various levels. Such a gesture can ride on the presidential scheme which has seen the distribution of computers to many disadvantaged rural and urban institutions of learning. Apart from UNICEF, other partnerships can be with United Nations Educational Scientific and Cultural Organisation (UNESCO), Non Governmental Organisations (NGOs) and even local thriving companies like Econet and Netone as well as mining, retailing and processing companies in Zimbabwe. Citizens urged government to formulate policies that favour the mushrooming and thriving of these companies and such other, and then enter into partnerships with them. These will pour subsidies for the publication and provision of a wide range of literature which meets the tastes of a variety of readers so as to elevate the reading culture among a people whose literacy levels it has raised.

Publishers pointed out another form of partnership in the form of marrying high selling textbooks with low selling ones, which address people's appetite for reading. In an interview with Chiwome (2002), Irene Staunton, founder of Weaver Press, Zimbabwe, argues that good novels could be subsidised by textbooks, which are the company's money spinners. A case in point is Choto's Vavariro, which was published out of such a partnership. This would not deter publishers from committing themselves to publishing useful books which may be deemed low fetching.

\subsection{Re-orienting the Zimbabwean language policy}

Speakers of indigenous languages like Shona and Ndebele clamoured for their raising to official status, like English. Those of previously marginalised languages like Xichangana, Venda, Kalanga, Nambya and Tonga proposed that they be accorded higher status, so that they are taught and examined at various levels of education. They all wished for more incentives for studying an indigenous language. What Uzochukwu (2005:32) recommends for lgbo language in Nigeria equally makes sense to the Zimbabwean situation. He says:

...it should be stipulated that a pass in Igbo should be a pre-requisite for obtaining the First School Certificate. At the secondary school level, getting a job or promotion or in some grades of the civil service should be contingent on passing Igbo in SSCE or GCE O/L; the same condition will be applied for an Igbo getting admission into any Arts-based programme in any tertiary institution. At the tertiary level, once a student is admitted to read lgbo, he/she should automatically be given a scholarship or be entitled to a bursary award. When all these measures are put in place, there will be adequate awareness of the need to study the language, and writing and publishing and general reading in it will surely be enhanced (italics, my own).

Indigenous language speakers called for a new language policy that makes it fashionable to study indigenous languages so that the majority of those who are shy today can proudly and seriously read literature published in these languages. This would also raise the craving for literature in these languages, consequently raising the reading culture among the people.

\subsection{Improving accessibility of serious literature}

Readers suggested the need for writers and publishers to have workshops on how to produce literature that focuses on what Achebe (1975) regards as the burning issues of the day. It is believed, holding such workshops would go a long way in increasing the relevance of writers and publishers in the societies they operate. Readers suggested that writers can be oriented on ways of exploring reality without lending themselves into trouble, and publishers made to appreciate such kind of literature. In traditional Shona, folktales were used to expose, criticise and call for behaviour change among its audience. Such styles as irony, sarcasm, comedy among others can be used to make society laugh at its vices and change for the better.

Readers further suggested that serious literature in Zimbabwe can be increased by translating good and thoughtprovoking literature from other language literatures into the languages accessible to the Zimbabwean readership. Notable works that were cited include Achebe's Things Fall Apart, Arrow of God, A Man of the People, Ngugi's Devil on the Cross, Matigari, Petals of Blood and p'Bitek's Song of Lawino and Song of Ocol they wished to be translated into indigenous languages like Shona, Ndebele, Venda and Xichangana so that they also benefit those not quite conversant with the English language. For this exercise to be successful, they suggested the need to establish a translation centre which oversees and undertakes the task using qualified personnel (Gudhlanga and Makaudze 2007:13-14).

$1202 \mid \mathrm{P}$ a g e

October 2016

https://cirworld.com/ 


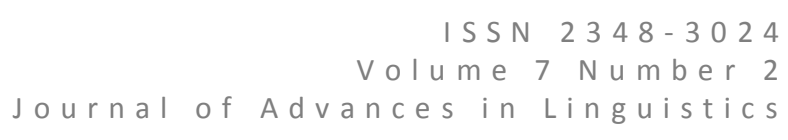

To improve accessibility of reading literature, several people suggested the introduction of community and school libraries where they are non-existent. It was noted that most communities, especially rural ones, did not have proper reading facilities. The suggestion was for community libraries to be built in every rural council and growth point for a start, and in schools. These would be made available at different hours or days, to both students and members of the community with a passion for reading. They noted that although most urban centres have City Council Libraries, the major setback was that the libraries were under-stocked; and in some cases, having old publications. Hence, there is great need to keep on stocking these libraries, by allocating a yearly budget for them.

\subsection{Improving marketing strategies for books}

Most people testified that why they did not enjoy reading was partly because they were not aware of the publications in circulation. They professed ignorance on the titles published in their areas of interest. They indicated that they could not all go to the bookshops to get fliers on any new publications in stock. Hence, they urged that, in an increasingly computerised and technology-driven environment, there was also need to adopt internet-based ways of marketing books. There was also need to take advertising to the print and visual media. They suggested that book titles be advertised in the midst of popular newspaper columns and television programmes. In addition, films, movies and cartoons could be modelled along story lines in given books so that those who watch television programmes are made keen to read the books.

\subsection{Conclusion}

Although Zimbabwe boasts of one of the highest literacy rates in Africa, the article has bemoaned the pathetic reading culture that exists. Through interviews and in-depth questionnaires, the possible underlying causes of such a state of affairs as well as the possible ways of trying to match the reading culture to the high levels of literacy that obtains were explored. It was observed that some of the reasons for the disparity include: emphasis on passing the examination, the high costs of buying books, the high cost of living, high costs of publishing and/or printing books for reading, the EnglishIndigenous language ambivalence, early orthographies and the marginalisation of other languages and paucity of serious works of art that illuminate life. Possible ways of balancing the high literacy rate and the reading culture which included: reorienting the education system, partnerships meant avail and subsidise the costs of publishing and/or printing books, reorienting the Zimbabwean language policy, improving accessibility of serious literature and improving marketing strategies for books.

\section{References}

Achebe, C. 1975. Morning Yet on Creation Day. London: Butler and Tanner.

Campbell, R. and Gwete, WB. 1998. Language Policy and Planning Module. Harare: University

College of Distance Education.

Chiwome, EM. 2002. A Social History of the Shona Novel. Gweru: Mambo Press.

Doke, CM. 1932. Report on the Unification of Shona Dialects. Hertford: Stephen Austin.

Gudhlanga, ES. and Makaudze, G. 2007. Writing and publishing in indigenous languages is a mere waste of time: a critical appraisal of the challenges faced by writers and publishers of Shona literature in Zimbabwe. Project for the Study of Alternative Education in South Africa (PRAESA) Occasional Paper, No. 26. PRAESA: University of Cape Town.

Mumpande, I. 2006. Silent Voices: Indigenous Languages in Zimbabwe. Harare: Weaver Press.

Munjanganja, LE. and Machawira, MS. 2014. Zimbabwe: Education for all 2015 national review, 4 January 2014.

NewZimbabwe. Zimbabwe has highest literacy rate in Africa: United Nations Development

Programme (UNDP). http//www.newzimbabwe.com. [Accessed on 29/04/2015].

Seddon, Q. 1966. The writer and the publishing business. In African Literature in Rhodesia, W. Krog (Ed). Gweru: Mambo Press. pp 80-100.

Shoko, J. 2014. Latest Zimbabwe education statistics embarrass ruling party. The Africa Report, 19 May 2014.

Tapureta, B. 2014. Is our reading culture dying? The Herald, 3 December 2014.

Uzochukwu, S. 2005. "The challenges of writing books in indigenous languages: The Igbo

experience." Nigerian Book Fair Trust, Publishing in Indigenous Languages. Lagos: Nigerian Book Fair Trust. Pp 23-33.

Zimbabwe Independent. Education: Literacy is not enough, 25 April, 2014. Pp 5.

Zimbabwe National Statistics Agency (ZimStat), 2013. Poverty and poverty datum analysis in Zimbabwe, 2011/2012. Harare. 


\section{(c) (i)}

This work is licensed under a Creative Commons Attribution 4.0 International License.

DOI : 10.24297/jal.v7i2.5155 